\title{
Ultrastructural development of the softwood cell wall during pyrolysis
}

\author{
Cordt Zollfrank $^{1, *}$ and Jörg Fromm ${ }^{2}$ \\ ${ }^{1}$ Department of Materials Science and Engineering-3, \\ Glass and Ceramics, University of Erlangen- \\ Nuremberg, Erlangen, Germany \\ 2 Institute for Wood Biology, Faculty of Biology, \\ University of Hamburg, Hamburg, Germany \\ ${ }^{*}$ Corresponding author. \\ Department of Materials Science and Engineering-3, \\ Glass and Ceramics, University of Erlangen-Nuremberg, \\ Martensstr. 5, D-91058 Erlangen, Germany \\ E-mail: cordt.zollfrank@ww.uni-erlangen.de
}

\begin{abstract}
The pyrolytic conversion of pine wood at mild temperatures between $200^{\circ} \mathrm{C}$ and $300^{\circ} \mathrm{C}$ was investigated by transmission electron microscopy (TEM). Based on TEM imaging and image analysis, a novel method was developed for determining the local orientation of the cellulose microfibrils in the secondary wall S2 which gives a measure for the progression of pyrolytic conversion of the cell wall. Elemental composition of pyrolysed specimens was determined up to $600^{\circ} \mathrm{C}$. TEM imaging together with the evaluation of the elemental composition shows that first the polyoses are degraded, while the cellulose microfibril orientation is still visible up to $225^{\circ} \mathrm{C}$. The cellulose microfibrils could not be observed at temperatures higher than $250^{\circ} \mathrm{C}$, while lignin containing compound middle lamella $(\mathrm{CML})$ was still visible. After a gradual decrease of the CML up to $275^{\circ} \mathrm{C}$, the cell wall became entirely isotropic beginning at $300^{\circ} \mathrm{C}$. Based on the presented results, we propose an early degradation of the supramolecular structure of the cell wall.
\end{abstract}

Keywords: cell wall; elemental analysis; softwood pyrolysis; transmission electron microscopy.

\section{Introduction}

Knowledge of the pyrolytic transformation of wood is substantial, among other things, to understand and to control the carbon production (Meier and Faix 1999; Antal and Gronli 2003). Wood derived carbons are of special interest as cellular templates for manufacturing novel ceramic materials with improved properties (Byrne and Nagle 1997b; Greil et al. 1998; Greil 2001). The replication of the original wood structure into the ceramic material has gained special attention for advanced materials manufacturing (Zollfrank and Sieber 2004, 2005).

Wood is a hierarchically structured biopolymer composed of partly crystalline cellulose microfibrils embedded in a matrix of polyoses and lignin which are arranged in several principal cell wall layers (Kollmann 1968; Fengel and Wegener 1984). During carbon production, the structure and chemical composition of the cell wall might directly affect the degrees of alignment and growth of developing graphene layers, i.e., the specific structural level of the cell wall and the carbonised material are closely related to each other (Paris et al. 2005). According to theoretical considerations, the orientation of cellulose microfibrils in the cell wall influences the graphene layer orientation in the carbon material. This theory has never been experimentally validated hitherto. However, the decomposition of the biopolymers in the wood cell wall during pyrolytic conversion (Goméz Diáz et al. 2007; Mészáros et al. 2007) and the subsequent structural development of the carbonaceous material has been investigated (Byrne and Nagle 1997a; Hata 1999; Kim et al. 2001; Hata et al. 2004; Paris et al. 2005; Zickler et al. 2006; Ishimaru et al. 2007b).

The present study is focused on the visualisation of the cell wall during wood pyrolysis at temperatures between $200^{\circ} \mathrm{C}$ and $300^{\circ} \mathrm{C}$ by transmission electron microscopy (TEM), which has not been described so far. Imaging of the cell wall by TEM is a powerful tool for the investigation of ultrastructural changes (Sugiyama et al. 1986). In an early study, Fengel (1978) measured a rather broad distribution of fibril diameters in delignified spruce with high statistical accuracy from TEM images. Optical diffraction methods and image analysis of cellulose protofibrils provided structural information on orientation and texture of fibrils (Tsuji and Manely 1984). In a successive study, digital correlation methods were applied for measuring the lateral distance between two streaks in the diffraction pattern to determine the interfibrillar distance of the cellulose fibrils (Tsuji and Manely 1986). TEM images can be recorded digitally or are digitised from a bright field micrograph. These data are subsequently Fourier transformed and digitally evaluated (Buseck et al. 1988).

Jakob et al. (1995) subjected TEM micrographs to a fast Fourier transformation (FT) algorithm to evaluate size and arrangement of the cellulose microfibrils in original wood. The applied procedure corresponds to the wellknown optical diffraction technique. The digitally produced 'diffraction pattern' of an object - similar to an electron diffraction pattern - contains the distribution of the spatial frequencies present in this input object (Gorecki 1989). In our case, the textural elements in the TEM micrographs are the cellulose microfibrils in the secondary cell wall (S2) which are visible in tangential sections as streaks after contrasting with heavy metal ions, such as $\mathrm{Pb}$ ". The TEM micrographs from the S2 layer were converted into FT images.

The higher frequency observed in particular areas in the FT images can be taken as a measure for a distinct angular distribution of the streaks in the TEM micrographs. Because the streaks are directly correlated to the 
cellulose microfibrils, their orientation can be obtained from angular fitting of the FT images [two-dimensional (2D) Gauss fitting]. As a result, spatial frequency of orientation distribution was taken as a quantitative measure for the cellulose microfibril angle (MFA) as a function of the deviation from the growth direction. The evaluation of TEM images permitted the monitoring of the progress of thermal conversion. In this way, the progress of pyrolysis could be observed.

\section{Materials and methods}

\section{Wood material and heat treatment}

Scots pine (Pinus sylvestris L.) samples with dimensions of $10 \times 25 \times 25 \mathrm{~mm}^{3}$ (axial $\times$ rad. $\times$ tang.) were extracted in a Soxhlet apparatus: first with toluene:ethanol $(2: 1 \mathrm{v} / \mathrm{v})$ for $12 \mathrm{~h}$ and subsequently with ethanol for $12 \mathrm{~h}$. Then, a hot water extraction followed for $6 \mathrm{~h}$ to decrease the content of inorganic matter and to minimise their influence on the pyrolytic behaviour. The extracted samples were dried at $105^{\circ} \mathrm{C}$ for $12 \mathrm{~h}$. Subsequently, the samples were weighed and their dimensions were determined. The samples were placed in a furnace (Heraeus, type $\mathrm{K} 1251)$ equipped with an alumina $\left(\mathrm{Al}_{2} \mathrm{O}_{3}\right)$ tube continuously flushed with nitrogen. Heat treatments were performed in the range from $200^{\circ} \mathrm{C}$ to $300^{\circ} \mathrm{C}$ in steps of $25^{\circ} \mathrm{C}$, and from $350^{\circ} \mathrm{C}$ to $600^{\circ} \mathrm{C}$ in steps of $50^{\circ} \mathrm{C}$. The temperatures were measured just above the samples with a thermocouple. The heating rate was $2^{\circ} \mathrm{C} \mathrm{min}^{-1}$ and the peak temperature was maintained for $2 \mathrm{~h}$. The mass loss and the dimensional changes were determined at room temperature.

\section{Elemental analysis}

The elemental composition of selected samples was determined by an elemental analyser (CHN-O Rapid, Heraeus). The data of elemental analysis are given in atomic \%.

\section{TEM imaging and image analysis}

Approximately 1-2 mm segments of heat treated wood samples were embedded in Spurr's epoxy resin (Spurr 1969). Ultrathin sections with a thickness of 70-80 nm of the tangential planes of the wood samples were obtained with a diamond knife on an ultramicrotome (Reichert-Jung, Ultracut E) and stained for 10 min with $1.0 \% \mathrm{~Pb}^{\prime \prime}$ citrate solution. The ultrathin sections were transferred onto Cu-grids coated with the polymer Form$\operatorname{var}^{\circledR}$ (Plano).

Bright field micrographs were recorded on Kodak SO-163 emulsion in a TEM (Philips CM 30) operated at $200 \mathrm{kV}$. The TEM micrographs of the same magnification were selected and digitised with a commercial scanner (hp scanjet 7400c) with 600 dots per inch by transmitted light. Images with a size of $512 \times 512$ pixels were selected from the digitised TEM micrographs from the $\mathrm{S} 2$ region of the cell wall. A fast FT was performed on the digitised images by the Scion image software (beta 4.0.2, Scion Corporation). A 2D Gaussian fit of the FT images in a defined circular segment (inner radius: 60 pixels; outer radius: 160 pixels) over the whole angular range $\left(0^{\circ}-360^{\circ}\right)$ was performed (FIT 2D software, Andy Hammersley, ESRF, Grenoble) to determine the angular distribution of the spatial frequencies corresponding to cellulose microfibrils of the input micrographs. The measured angles from spatial frequency distributions of the 2D Gaussian fits were corrected according to the inclination angle of the growth direction with respect to the scanned TEM micrographs. The growth direction was distinctly defined in the TEM micrographs by the compound middle lamellae $(\mathrm{CML})$ on the tangential sections. This procedure was performed on at least 15 FT images obtained from different regions in the $\mathrm{S} 2$ cell wall layer. A separate file was generated to correct the influence of the background and deviations from the Formvar $^{\circledR}$ support film. That is, FT and 2D fit were performed on TEM micrographs taken in an area close to the edge of the cell wall within the ultrathin section. Thus, only spatial frequencies derived from the cellulose microfibril orientation in the FT images were evaluated.

\section{Results and discussion}

The total mass loss after heating the pine wood samples to $600^{\circ} \mathrm{C}$ accounted for $75 \%$, and the anisotropic shrinkage in the various directions showed the expected values (axial 18\%, radial 29\%, tangential 33\%, Fengel and Wegener 1984). The main mass loss and shrinkage occurred between $200^{\circ} \mathrm{C}$ and $400^{\circ} \mathrm{C}$. The $\mathrm{C}, \mathrm{H}$, and $\mathrm{O}$ contents were nearly unchanged up to $250^{\circ} \mathrm{C}$ (Figure 1a). However, at $300^{\circ} \mathrm{C}$ the $\mathrm{C}$ value increased from $33.9 \%$ to $48.5 \%$, while the $\mathrm{H}$ and $\mathrm{O}$ contents decreased from $46.0 \%$ to $39.5 \%$ and from $20.0 \%$ to $11.8 \%$, respectively. Later on, the $\mathrm{C}$ content rose to $63.3 \%$ and the $\mathrm{H}$ content decreased to $30.6 \%$, while $\mathrm{O}$ was diminished to $6.1 \%$ at $500^{\circ} \mathrm{C}$. The pine wood samples still contain substantial amounts of hydrogen and oxygen after pyrolysis at $600^{\circ} \mathrm{C}$. The $\mathrm{H} / \mathrm{C}$ atomic ratio is steadily diminished from 1.5 to 0.5 between $200^{\circ} \mathrm{C}$ and $500^{\circ} \mathrm{C}$ (Figure $1 \mathrm{~b}$, van Krevelen 1950), while the $\mathrm{O} / \mathrm{C}$ atomic ratio decreased from 0.7 to 0.1 . At temperatures higher than $300^{\circ} \mathrm{C}$, the fast decrease of the $\mathrm{H} / \mathrm{C}$ and the O/C ratios slowed down. Our data for lower temperatures complement the values for temperatures higher than $600^{\circ} \mathrm{C}$ previously published by Ishimaru et al. (2007a).

The thermal degradation of the cell wall up to a temperature of $300^{\circ} \mathrm{C}$ was investigated by TEM (Figure 2). The typical appearance of a tangential section of an original softwood cell wall stained with $\mathrm{Pb}$ " citrate is shown in Figure 2a. The lignin rich middle lamella and the two bordering primary walls are hardly discernible from each other. Together, they form the CML, which is visible as a dark layer. The adjacent secondary wall S1 is brightest due to the much lower lignin content. A change in cellulose microfibril direction indicates the transition between $\mathrm{S} 1$ and $\mathrm{S} 2$ accompanied by an increase in lignin concentration (Fromm et al. 2003). In the S2 the cellulose microfibrils form numerous layers with helical orientations and different helical pitches. The orientation of the cellulose microfibrils is characterised by the MFA which are usually between $0^{\circ}$ and $30^{\circ}$ (Lichtenegger et al. 1999). Their orientation is clearly visible from the dark stained streaks in the TEM micrographs.

Hitherto, the distribution of the angular orientation of the cellulose microfibrils in the wood cell was not evaluated. In the present paper, image analysis permitted this type of quantitative evaluation. The obtained FT images revealed two broad frequency distributions nearly perpendicular to the growth direction (see insets in Figure $2 a-c)$. The observed spatial frequencies are a direct measure for the distance between two neighbouring streaks in the input images, i.e., the orientation of cellu- 


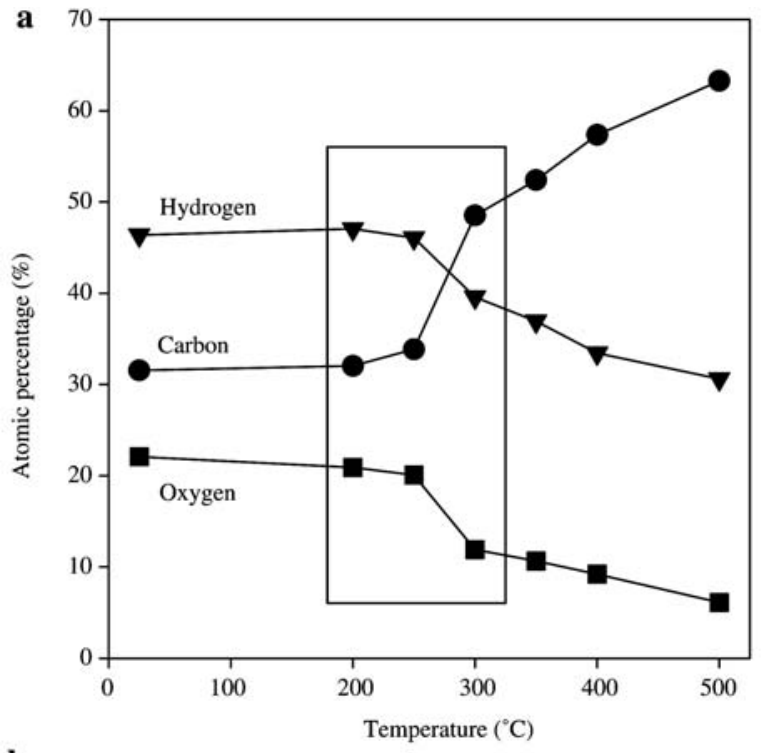

b

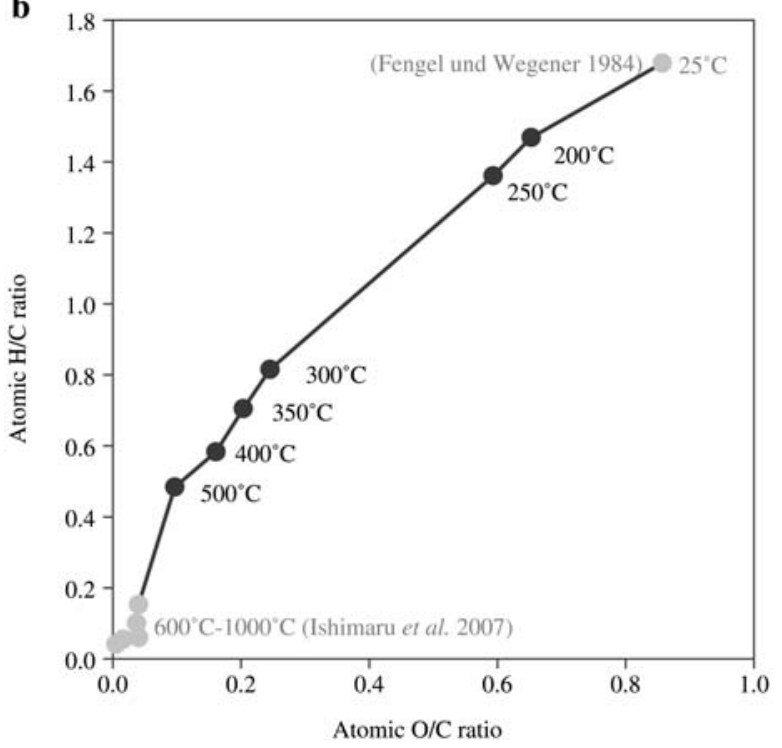

Figure 1 (a) Development of carbon, oxygen and hydrogen content with increasing temperature; the important temperature range is highlighted by the square; (b) van Krevelen (1950) diagram of the $\mathrm{H} / \mathrm{C}$ to $\mathrm{O} / \mathrm{C}$ ratios; data points in black obtained in this study, data points in grey are according to Fengel and Wegener (1984) and Ishimaru et al. (2007a).

lose microfibrils. The resulting averaged angular distribution of fitted intensities was plotted with respect to the growth axis (Figure 2a). The subsequently applied curve fit showed a maximum at $7^{\circ}$ [full width at half maximum (FWHM): $15^{\circ}$ ], which corresponded particularly well to the general orientation of the cellulose microfibrils in the S2 in softwoods (Fengel and Wegener 1984).

The TEM micrographs taken from a cell wall section of wood treated at $200^{\circ} \mathrm{C}$ showed in principle the same structural features as the original cell wall in the CML, the $\mathrm{S} 1$, and the S2 (Figure 2b). The 2D Gaussian fit of the derived FT images yielded an angular distribution plot, where the fitted curve displays a maximum at an inclination angle of $4^{\circ}\left(\mathrm{FWHM}: 45^{\circ}\right)$. The distribution of the angular orientation of the cellulose microfibrils appears broadened due to the beginning degradation of the polyoses. The additional free space created by degra-
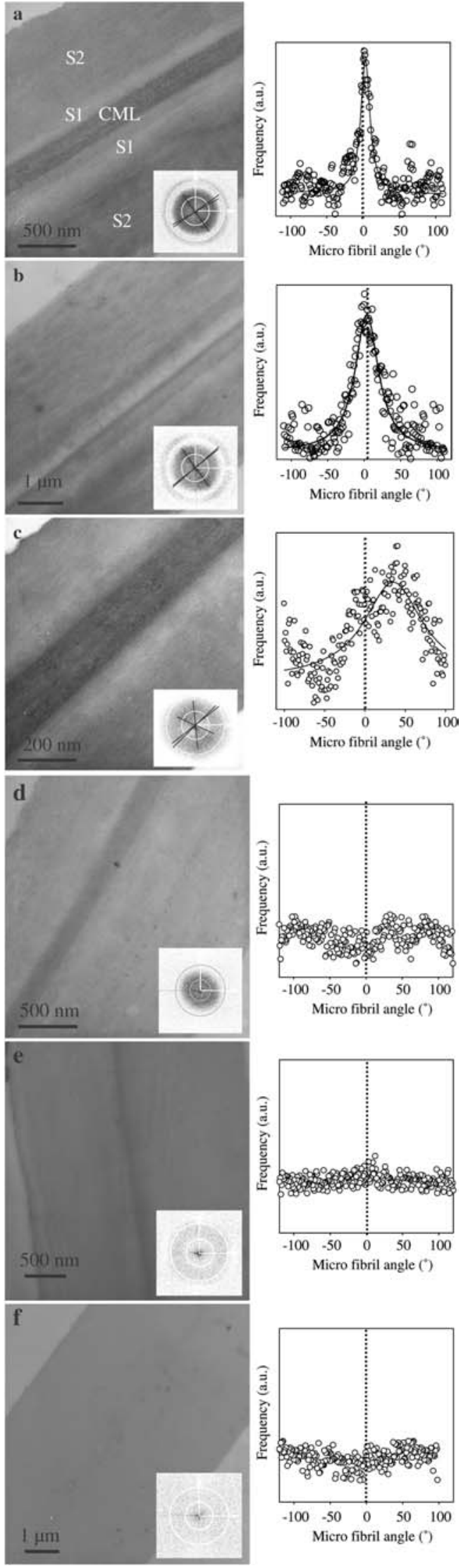

Figure 2 TEM micrographs of tangential sections and corresponding plot of the angular cellulose microfibril orientation distribution (solid lines are drawn as a guide for the eye) of a) original pine wood and pyrolytically converted pine wood at b) $200^{\circ} \mathrm{C}$, c) $225^{\circ} \mathrm{C}$, d) $250^{\circ} \mathrm{C}$, e) $275^{\circ} \mathrm{C}$, and f) $300^{\circ} \mathrm{C}$; insets in all figures show a representative $\mathrm{FT}$ image of a region of interest from the $\mathrm{S} 2$ cell wall layer. 
dation might be filled with the remaining cellulose fraction yielding a limited reorientation of the microfibrils. The basic structural features, such as the CML, the $\mathrm{S} 1$, and $\mathrm{S} 2$ were still observed up to $225^{\circ} \mathrm{C}$ (Figure 2c). The measured spatial frequency distribution was substantially increased to a FWHM of $52^{\circ}$. The peak maximum was shifted to an inclination angle of $36^{\circ}$. The orientation distribution of the cellulose microfibrils is now very broad due to the beginning degradation of the cellulose and proceeding decay of the polyoses.

The image contrast from the CML in the TEM micrographs was diminished after heating to $250^{\circ} \mathrm{C}$ (Figure 2d). Fading of the CML was even more pronounced at $275^{\circ} \mathrm{C}$, where it was only visible as a thin band between two cells (Figure 2e). The width of the CML decreased from $\sim 400 \mathrm{~nm}$ (original wood) to $\sim 200 \mathrm{~nm}$ at $250^{\circ} \mathrm{C}$ and to $\sim 100 \mathrm{~nm}$ at $275^{\circ} \mathrm{C}$. The observed contrast in the images from staining indicates that part of the original wood structure was still maintained. This is not valid for the cellulose microfibrils, because the evaluation of the FT images from the cell walls and 2D Gaussian fits resulted in a straight line. A distinct angular frequency distribution could not be observed any longer at $275^{\circ} \mathrm{C}$. Rather, a broad ring pattern in the FT images obtained from wood treated at $300^{\circ} \mathrm{C}$ indicates a pronounced isotropy with a homogeneous and disordered cell wall structure (Figure 2f). There are no discernible structural features derived from the secondary wall. The former CML could not be identified, only an extremely faint line was present in some cases. The contrast in the TEM was low and uniform probably due to the lack of staining sites for the $\mathrm{Pb}^{\prime \prime}$ ions. As a consequence, the FT images from digitised micrographs exhibited a uniform appearance without any frequency distribution or ring patterns. This indicates a complete loss of structure, even short range orders are missing. The cell wall structure is apparently fully disordered down to the molecular level. Similar observations are described by Paris et al. (2005). The sudden change between the presence of well oriented and disordered structural elements in the cell wall is remarkable. There are at least two interpretation possibilities for this observation:
1) The first one is presented in Figure 3. Four different stages of the ultrastructural development during thermal treatment of the softwood cell wall are depicted. a) From $25^{\circ} \mathrm{C}$ to $200^{\circ} \mathrm{C}$ : no ultrastructural changes of the original cell wall (Figure $3 \mathrm{a}$ ). b) Up to $225^{\circ} \mathrm{C}$ : partly depolymerisation of the polyoses and increased disorder of the cellulose microfibrils occur. The lignin rich $\mathrm{CML}$ remained optically nearly unchanged (Figure 3b). c) From $250^{\circ} \mathrm{C}$ to $275^{\circ} \mathrm{C}$ : the crystallite size declines (Zickler et al. 2007) and this is accompanied by an iso-orientation of the cellulose microfibrils (loosing their preferred orientation with a specific MFA) and the CML is also decomposed (Figure 3c). d) $300^{\circ} \mathrm{C}$ : amorphisation of the cell wall proceeds to a disintegrated and fully random structure (Figure $3 d$ ).

2) It is also possible that the heavy (non-volatile) tars formed in early stages of pyrolysis (around $250^{\circ} \mathrm{C}$ and $300^{\circ} \mathrm{C}$ ) mask the remaining cellulosic structures so that they are not visible by TEM. It is well known from differential thermogravimetry analysis (DTA) that dehydration and splitting of functional groups, which is readily perceptible by the emission of fragments with low molecular masses (volatiles) in thermogravimetry/mass spectrometry studies, are the predominant reactions up to $250^{\circ} \mathrm{C}$ and $270^{\circ} \mathrm{C}$ (Goméz Diáz et al. 2007; Mészáros et al. 2007). A detectable shoulder at $300^{\circ} \mathrm{C}$ in the DTA indicates the beginning of a vehement splitting of all essential chemical bonds and a total rearrangement of the organic material to a carbonaceous one accompanied by the formation of heavy tars. Consequently, the formed tars might cover the remaining microfibrillar cellulose increasing the apparent homogenisation of the cell wall.

Kim et al. (2001) proposed first models on the thermally induced decomposition of cellulose microfibrils in wood including reduction of crystallinity (cellulose decomposition) along the fibre axis and rapid decomposition of individual microfibrils, while others are still intact. Recently, Zickler et al. (2007) anticipated another model involving degradation starting from the equatorial surfaces of the cellulose crystallites, where initial decomposition should occur at the boundaries between the cellulose microfibrils and the polyoses. However, EM studies on wood treated at mild temperatures are scarce in the literature.

Temperature

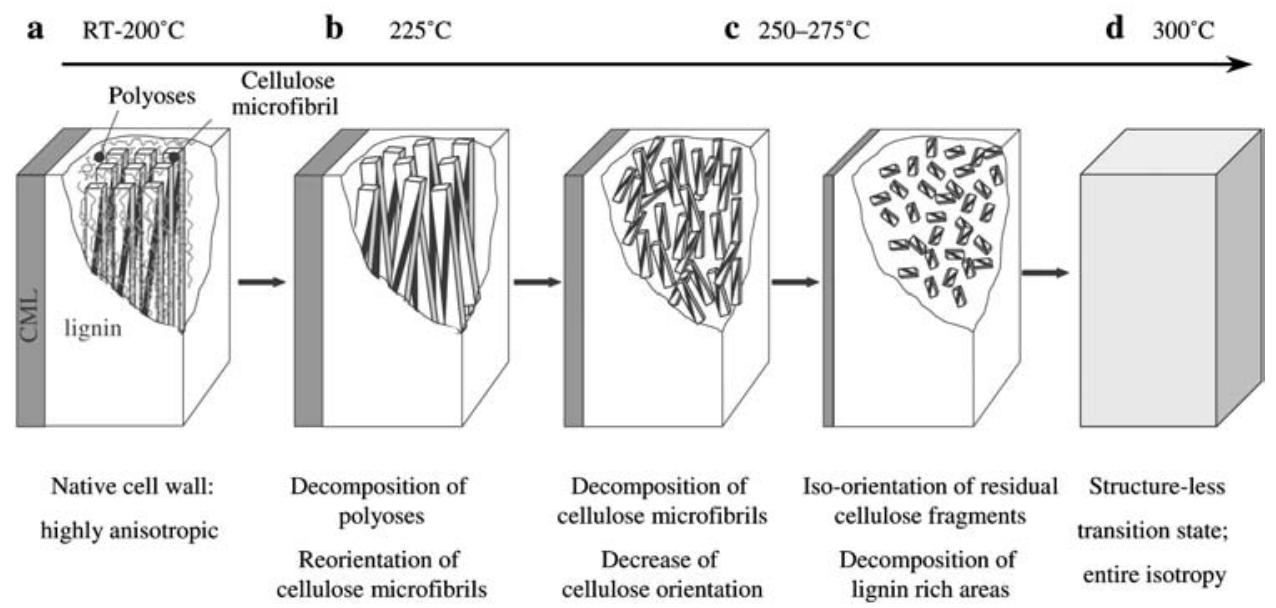

Figure 3 Proposed model for the ultrastructural development of the softwood cell wall during pyrolytic conversion at mild temperatures: a) room temperature to $200^{\circ} \mathrm{C}$, b) $225^{\circ} \mathrm{C}$, c) $250-275^{\circ} \mathrm{C}$, and d) $300^{\circ} \mathrm{C}$. 
Only a few TEM studies were dedicated to the analysis of carbonised wood and the thermally induced structural evolution of the original wood cell wall obtained at temperatures exceeding $600^{\circ} \mathrm{C}$ (Hata et al. 2000, Hata et al. 2004; Ishimaru et al. 2007b).

It is well known that the polyoses surrounding the cellulose microfibrils are denaturated by scission of functional groups above $200^{\circ} \mathrm{C}$. Potentially, the paracrystalline (amorphous) parts of the cellulose are also degraded early to a certain degree. The decomposition of polyoses and cellulose is clearly separated in the case of the wood according to kinetic pyrolysis investigation by Mészáros et al. (2007). The free volume created by polyoses degradation can be refilled by the remaining microfibrils due to their increased mobility. Non-volatile tars are also formed at this stage which can fill up the additional space as well. However, the microfibrils in the temperature treated wood appear less oriented and less visible - possibly due to a cover with non-volatile tars than in the original wood as shown by strong broadening of the orientation distribution (FT) in Figure 2c. The resulting microfibril fragments have larger MFA. With increasing temperatures, the crystalline part of the cellulose is also degraded by various mechanisms (Zickler et al. 2007) which finally leads to a complete loss of detectable orientation.

The CML is still present at elevated temperatures because lignin degrades at higher temperatures than the polyoses (Fengel and Wegener 1984). Infrared spectroscopy reveals (Zollfrank and Paris 2003) that residual, oligomeric fragments of the cellulose microfibrils were still present at $275^{\circ} \mathrm{C}$, but in an iso-oriented state (Figure $2 \mathrm{e})$. These remaining structures can possibly be covered by heavy tars obscuring their detection in the TEM. However, the original cell wall becomes completely structureless at $300^{\circ} \mathrm{C}$ (Figure $2 \mathrm{f}$ ), as was already proposed by Paris et al. (2005). Since amorphous compounds, such as the developed heavy tars, do not contribute to X-ray diffraction, possible masking effects from non-volatiles are less probable at this stage.

\section{Conclusions}

Based on TEM micrographs and their novel quantitative image analysis, the pyrolytic conversion of pine wood was investigated at temperatures between $200^{\circ} \mathrm{C}$ and $300^{\circ} \mathrm{C}$. Two essential stages concerning the ultrastructural development in the cell wall could be detected: 1) a preferable degradation of polyoses and the paracrystalline moiety of cellulose and modification of lignin, and 2) transformation of the cell wall into a disordered, amorphous network formed of $\mathrm{C}, \mathrm{H}$, and $\mathrm{O}$ atoms. It is proposed that the apparently homogenised cell walls might consist of non-crystalline cellulosic fragments and nonvolatile tars from biopolymer degradation. TEM imaging indicates that the development of the substructures in wood-derived carbons are not necessarily closely related to the original ultrastructure of the wood. Full or partial orientation of developed graphene layers is consequently the result of an intrinsic process possibly driven by surface constraints within the cell wall layers. To our knowl- edge, the presented image analysis was used for the first time for the spatially resolved distribution analysis of cellulose microfibril orientation in thermally treated wood. Such studies are important for designing novel carbons based on wood or other biomass with a defined structure, e.g., graphitic and random oriented carbons.

\section{Acknowledgements}

The authors wish to thank Professor Dr. Oskar Faix for many helpful discussions. The use of the transmission electron microscopes at the Central Facility for Electron Microscopy of the Friedrich-Alexander-University of Erlangen-Nuernberg and the technical assistance of Mrs. Tanja Potsch, Institute for Wood Technology and Biology, Von-Thünen-Institute Hamburg-Bergedorf, is gratefully acknowledged.

\section{References}

Antal, M.J. Jr, Gronli, M. (2003) The art, science, and technology of charcoal production. Ind. Eng. Chem. Res. 42:1619-1640.

Buseck, P.R., Epelboin, Y., Rimsky, A. (1988) Signal processing of high-resolution transmission electron microscope images using Fourier transforms. Acta Cryst. A44:975-986.

Byrne, C.E., Nagle, D.C. (1997a) Carbonization of wood for advanced materials applications. Carbon 35:259-266.

Byrne, C.E., Nagle, D.C. (1997b) Cellulose derived composites - a new method for materials processing. Mater. Res. Innov. $1: 137-144$.

Fengel, D. (1978) On the fibrillar structure of cellulose from wood. Holzforschung 32:37-44.

Fengel, D., Wegener, G. Wood: Chemistry, Ultrastructure, Reactions. De Gruyter, Berlin, 1984.

Fromm, J., Rockel, B., Lautner, S., Windeisen, E., Wanner, G. (2003) Lignin distribution in wood cell walls determined by TEM and backscattered SEM techniques. J. Struct. Biol. 143:77-84.

Goméz Diáz, C.J., Mészáros, E., Jakab, E., Velo, E., Puigjaner, L. (2007) Thermogravimetry/mass spectrometry study of woody residues and an herbaceous biomass crop using PCA techniques. J. Anal. Appl. Pyrol. 80: 416-426.

Gorecki, C. (1989) Optical sizing by Fourier transformation. J. Optics (Paris) 20:25-29.

Greil, P. (2001) Biomorphous ceramics from lignocellulosics. J. Eur. Ceram. Soc. 21:105-118.

Greil, P., Lifka, T., Kaindl, A. (1998) Biomorphic cellular silicon carbide ceramics from wood: I. Processing and microstructure. J. Eur. Ceram. Soc. 18:1961-1973.

Hata, T. (1999) Microstructural analysis of biocarbon from wood. Cellulose Comm. 6:27-133.

Hata, T., Vystavel, T., Bronsveld, P., De Hosson, J., Kikuchi, H., Nishimiya, K., Imamura, Y. (2004) Catalytic acrbonization of wood charcoal: graphite or diamond? Carbon 42:961-964.

Ishimaru, K., Hata, T., Bronsveld, P., Meier, D., Imamura, Y. (2007a) Spectroscopic analysis of carbonization of wood cellulose and lignin. J. Mater. Sci. 42:122-129.

Ishimaru, K., Hata, T., Bronsveld, P., Imamura, Y. (2007b) Microstructural study of carbonized wood after cell wall sectioning. J. Mater. Sci. 42:2662-2668.

Jakob, H.F., Fengel, D., Tschegg, S.E., Fratzl, P. (1995) The elementary cellulose fibril in Picea abies: comparison of transmission electron microscopy, small-angle X-ray, scattering, and wide-angle $\mathrm{X}$-ray scattering results. Macromolecules 28:8782-8787.

Kim, D.Y., Nishiyama, Y., Wada, M., Kuga S., Okano, T. (2001) Thermal decomposition of cellulose crystallites in wood. Holzforschung 55:521-524. 
Kollmann, F.F.P., Coté, W.A. Jr. Principles of wood science and technology. Springer, New York, 1968, p. 18.

Lichtenegger, H., Reiterer, A., Stanzl-Tschegg, S.E., Fratzl, P. (1999) Variation of cellulose microfibril angles in softwoods and hardwoods - A possible strategy of mechanical optimization. J. Struct. Biol. 128:257-269.

Meier, D., Faix, O. (1999) State of the art of applied fast pyrolysis of lignocellulosic materials - a review. Bioresource Technol. 68:71-77.

Mészáros, E., Jakab, E., Várhegyi, G., Tóvári, P. (2007) Thermogravimetry/mass spectrometry analysis of energy crops. J. Therm. Anal. Calor. 88:477-482.

Paris, O., Zollfrank, C., Zickler, G.A. (2005) Decomposition and carbonisation of wood biopolymers - a microstructural study of softwood pyrolysis. Carbon 43:53-66.

Spurr, A.R. (1969) A low viscosity epoxy resin embedding medium for electron microscopy. J. Ultrastruct. Res. 26:31-43.

Sugiyama, J., Otsuka, Y., Muarse, H., Harada, H. (1986) Toward direct imaging of cellulose microfibrils in wood. Holzforschung 40(Suppl):31-36.

Tsuji, M., Manley, R.S.J. (1984) Image analysis in the electron microscopy of cellulose protofibrils. Coll. Polym. Sci. 262: 236-244.

Tsuji, M., Manley, R.S.J. (1986) Image analysis in the electron microscopy of cellulose protofibrils II. Digital correlation methods. Coll. Polym. Sci. 264:89-96. van Krevelen, D.W. (1950) Graphical-statistical method for the study of structure and reaction processes of coal. Fuel 29: 269-284.

Zickler, G.A., Smarsly, B., Gierlinger, N., Peterlik, H., Paris, O. (2006) A reconsideration of the relationship between the crystallite size $L_{a}$ of carbons determined by $\mathrm{X}$-ray diffraction and Raman spectroscopy. Carbon 44:3239-3246.

Zickler, G.A., Wagmaier, W., Funari, S.S., Burghammer, M., Paris, O. (2007) In-situ investigation of thermal decomposition of wood cellulose. J. Anal. Appl. Pyrolysis 80:134-140.

Zollfrank, C., Paris, O. (2003) Thermal degradation of wood and microstructure of biocarbon. In: Proceedings of the 12th International Symposium on Wood Pulping Chemistry. Vol. 1. University of Wisconsin, Madison, Wl. pp. 349-352.

Zollfrank, C., Sieber, H. (2004) Microstructure and phase morphology of wood derived biomorphous SiSiC-ceramics. J. Eur. Ceram. Soc. 24:495-506.

Zollfrank, C., Sieber, H. (2005) Microstructure evolution and reaction mechanism of biomorphous SiSiC-ceramics. J. Am. Ceram. Soc. 88:51-58.

Received April 9, 2008. Accepted September 11, 2008.

Previously published online November 10, 2008. 